\title{
Conversations and Reflections on Authentic Assessment
}

\author{
Kimberley Grant, Lisa Fedoruk, and Lorelli Nowell, University of Calgary, \\ Canada
}

\begin{abstract}
In this paper, we describe how academic colleagues from different fields used a theoretical framework for authentic assessment as the starting point for meaningful conversations about our teaching practices. We re-envision Hutchings' (2000) taxonomy of SoTL questions as a fluid conversational cycle rather than a system of classification. Using the eight elements of authentic assessment as outlined by Ashford-Rowe et al. (2014) as a theoretical framework, we engage with the research literature, reflect on what is and what works from our previous teaching and learning experiences, and propose ideas and questions for what is possible moving forward.
\end{abstract}

Keywords: conversation, authentic assessment, reflection 


\section{INTRODUCTION}

One of the most encouraging and helpful insights for those engaging with the Scholarship of Teaching and Learning (SoTL) is the idea that conversations matter and that "significant conversations" with trusted colleagues can help shape our understandings about teaching and learning (Roxå \& Mårtensson, 2009). In our experience, many collegial conversations about teaching and learning tend to circle around one, or a fluid combination, of the questions posed in Hutchings' (2000) often-cited taxonomy of SoTL research inquiry:

- What works?

- What is?

- What is possible?

- What kinds of theoretical frameworks can we formulate?

While the taxonomy offers a useful way to classify and structure SoTL studies, we notice that these questions are also present, explicitly or implicitly, when academics discuss their teaching. These conversations often start with descriptions of what is currently happening in our classrooms or teaching practice. Then, because academics are well trained in critical analysis, we often frame our descriptions around another provocative SoTL question: "What's the problem?" (Bass, 1999). Thus, we have found that our conversations tend to follow a fairly predictable model. Someone shares an anecdote about something happening in their class. If that anecdote is presented as "here is what works," then others are likely to ponder what is possible in terms of how they can adapt or adopt that strategy in their own classes. If, however, the anecdote is framed as a problem, then they are likely to jump into problem-solving mode and start wondering what works or what is possible in such a situation. Only if there is sufficient time and energy to pursue the original question more formally are such conversations likely to turn to formulating new conceptual frameworks.

This paper, however, came to be because we found ourselves in a different mode of conversation, and it was unusual enough to draw our attention to it. This conversation, or rather a series of ongoing conversations, started in an unlikely way: with a discussion of a theoretical framework of authentic assessment. While we were talking about the principles of the framework, our conversation centred on stories of resonance more than posing questions or solving problems. We discussed what works by reflecting on past teaching experiences in light of this new-to-us conceptual framework. We began sharing particulars of what is in terms of current practices in our fields. Rather than settle for comparisons of effective practices, however, these conversations opened up reflections on what is possible moving forward, both in our individual practices and in our fields. Thus, we literally and figuratively brought the questions in Hutchings' (2000) taxonomy into conversation with each other. We have depicted these questions in cyclical rather 
than linear relationship because we found that as the conversation continues through multiple cycles of these questions, the momentum and impetus continue to come from the conceptual framework of authentic assessment.

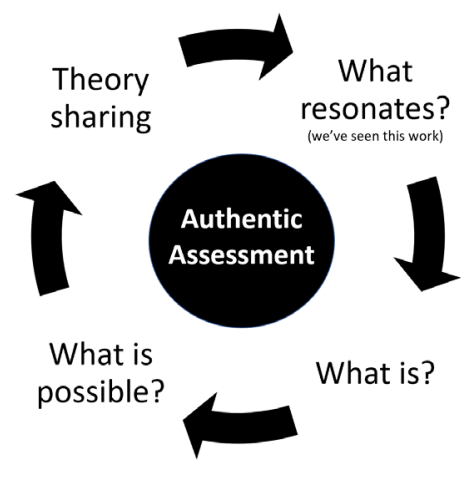

While we want to share our learning about authentic assessment strategies across fields and contexts, we also aim to foreground the type of conversation that helped this learning become visible. Therefore, we use the above model as a way to convey how our conversations about authentic assessment spurred new learning and deepened our ability to reflect on and articulate our teaching experiences. We begin by describing who we are as conversation partners, then we explain how the principles of authentic assessment resonate with stories and strategies of our teaching experiences as well as how they inspire new questions and explorations of what may be possible moving forward.

\section{The Conversation Partners}

We are academics at the University of Calgary, a medium-sized research university in western Canada, and we previously worked together at a teaching and learning institute in the field of educational development. Although our roles have changed, we still meet regularly. We come to conversations about teaching and learning with different professional and academic experiences and tend to draw heavily on examples from our specific fields and teaching experiences. Kimberley (Kim) Grant has taught in a pre-service teacher education program and now leads a graduate teaching development certificate program. Lisa Fedoruk also comes from the field of education and is an experienced adult educator with expertise in cross-cultural teaching and learning. Lorelli Nowell comes from the field of nursing and has extensive experience teaching and mentoring in both undergraduate and graduate nursing programs. 
Kim initiated these conversations to learn more about the others' experiences with the concepts and practices of authentic assessment. Having been introduced to the terminology and framework of authentic assessment in the context of preservice teacher education, she wanted to know how these practices and ideas might resonate in others' teaching experiences. Building on a foundation of frequent informal conversations, these intentional conversations were characterized by the traits described by Roxå \& Mårtensson (2009) as central to significant conversations: private, trustful, supportive, and intellectually intriguing. What began as a private conversation, however, has inspired us to bring others into this discussion. This collaborative sharing of ideas, we believe, is the power of significant conversations in SoTL.

\section{The Conversation Topic: Authentic Assessment}

While incorporating the language and concepts of authentic teaching, learning, and assessment has become more common in higher education in recent years (Fook \& Sidhu, 2010; Gulikers et al., 2004; Haynes, 2010; Herrington, 2006; Villarroel et al., 2018), the term authentic assessment is attributed to an essay written by Grant Wiggins (1990). Wiggins appeals to educators to focus on "worthy intellectual tasks" (p. 1) that, unlike standardized multiple-choice tests, include aspects of performance, complexity, and ambiguity. Many subsequent definitions relate authentic assessment tasks to real-world applications of knowledge rather than classroom-focused activities (Ashford-Rowe et al., 2014; Burrack, 2018; Gulikers et al., 2004). Proponents of authentic assessment argue traditional assessments that test recall of isolated pieces of information are insufficient for students to develop the skills to utilize and synthesize knowledge in real world contexts (Burrack, 2018; Koh et al., 2012; Wiggins, 1993).

As we were discussing the concept of authentic assessment, we agreed that while the language and theoretical framework may be new to us, the principles resonated with our lived experiences of teaching. We talked about how different aspects of authentic task design and assessment were already at play in our practices and in our fields. Rather than focusing on current questions or problem solving, our conversations provided a new lens through which to reflect on past experiences and a common language with which to describe some of our most positive teaching and learning strategies.

We have organized the following sections around the eight elements of authentic assessment as described by Ashford-Rowe et al. (2014). While the eight elements are interwoven and overlapping, we address each separately. We describe each element briefly within the context of the theoretical framework and research literature, then we reflect on how these elements resonate within what is and what 
works from our teaching experiences, and finally we pose some ideas for what is possible for us and for higher education moving forward.

\section{Element \#1: An Authentic Assessment Should Be Challenging}

Ashford-Rowe et al. (2014) stated authentic assessment should be challenging, not just in the traditional sense of hard work, but also in alignment with real-world situations. Students must construct or produce meaning rather than simply recite what they have learned (Newmann et al.,1996). In light of this, we talked about the growing use of virtual learning environments and games in higher education. Complex virtual games used in higher education settings allow students to experience challenging situations and assume roles that may be inaccessible to novices in the real world. Virtual role-playing and multiplayer games provide authentic, engaging activities for students to develop problem-solving, decisionmaking, and collaboration skills without the barriers and risks of the real world (Oblinger, 2004).

LORELLI: The virtual learning space has been embraced by many nursing schools who are challenged with finding clinical placements within a limited number of healthcare spaces. Virtual simulations allow students to make meaningful choices, learn at their own pace, and repeat activities if necessary. Today's nursing students are much more comfortable with virtual learning, which provides standardized opportunities for students to master complex nursing skills that might not be available in clinical settings, such as decision making in life-ordeath situations, without causing patient harm.

KIM: In higher education, we often hear about the need to accelerate the use of technology in classrooms. Because technology is changing so rapidly, I think it is important to remember that technology is just a tool to support learning rather than an end in itself. We need to stay focused on our learning aims when we incorporate new tools, or it is easy to get sidetracked by whatever is new and shiny.

It may be possible to use virtual learning tools, while including multiple layers of embedded feedback, to scaffold complex, real-world learning (Nelles et al., 2011). While studies on Virtual Learning Environments (VLEs) have been ongoing for about a decade, we are still on the cusp of learning how to design effective, authentic learning tasks in these environments, whether they involve virtual microscopes (Herodotou et al., 2018), self-directed anatomy and physiology learning (Weaver et al., 2020), or problem-based learning in engineering (Bessa et al., 2019). 


\section{Element \#2: The Outcome of Authentic Assessment Should Be in the Form of a Performance or Product}

Thoughtful task design enables students to demonstrate their learning in a synthesized activity that, if adequately reflective of the field of study, nearly always includes variety, complexity, and creativity (Archbald \& Newmann, 1988; Ashford-Rowe et al., 2014). The term performance here is used in a particular way, emphasizing demonstrations of learning related to how people in the field apply knowledge. For example, mathematicians use equations to formulate proofs, not to answer exam questions. Thus, the process of formulating a proof is a performance, and the proof is a product. Depending on the context, instructors may decide to focus more on students producing a polished performance/product or on students demonstrating increasing skill with processes that will eventually lead to more successful authentic task completion (Gulikers et al., 2004).

LISA: In most professional disciplines, this element of authentic assessment is taken to mean that novices need opportunities to demonstrate their learning by actually working in the field, not just writing a paper about how this work occurs. For pre-service teachers, this involves teaching classes of students. In the performance of these activities, students learn how to apply and contextualize what they have learned, identify areas where they chose to deviate from their plans, and reflect on what they would do differently next time.

LORELLI: Similar to education, nursing is a practice-based profession that requires students to actually work in healthcare environments as part of the learning process. Nursing students work in groups of eight with one instructor and later one-on-one with a registered nursing preceptor to demonstrate their learning and skills development.

We became curious about what performances or products look like in other fields. It may be easier to conceive of authentic tasks and performances in the professional disciplines (Maxwell, 2012), but all disciplines have norms and practices that novices need to demonstrate. This challenges us to consider how application and theory can be contextualized for students at various stages in their learning in order to maintain the authenticity of assessment tasks.

\section{Element \#3: Authentic Assessment Design Should Ensure Transfer of Knowledge}

As educators, we aim to guide students to internalize and ultimately apply learning in real-world contexts. To foster this transfer of knowledge from theory to practice as well as across contexts, authentic assessment tasks should be consistent with the knowledge, skills, abilities, and attitudes required in real-world 
applications (Villarroel et al., 2018). Moving beyond traditional formal assessments (e.g., multiple-choice exams) requires educators to think deeply about constructing evaluative measures that are pedagogically reflective of real-world situations.

From an educational research perspective, transfer of knowledge is a complex, slippery concept as demonstrations of learning are always contextual (Hager \& Hodkinson, 2009). For example, we discussed how applying their learning in real world contexts often means students will not isolate discrete pieces of information but will integrate learning from multiple courses and experiences in order to address challenges. This relates to Ashford-Rowe et al.'s (2014) assertion that transfer of knowledge through authentic assessment should also "have meaning beyond the confines of a single content area" (p. 208).

LISA: While working closely with groups of pre-service teachers from Asia, we intentionally introduced students to Western pedagogies in a university classroom before asking them to transfer that knowledge to a Canadian community-based school. They combined their new learning with their previous experiences to make meaning beyond the specific tasks, incorporating a wide range of factors including educational policy, pedagogies, and overall student experiences. Although they were most familiar and comfortable with instructor-focused pedagogies, they were able to draw on learning-centred strategies like in-class debate and group discussions.

LORELLI: In nursing education we try to scaffold learning by integrating theory into real-life nursing practice. For example, in one week, students may learn about the anatomy and physiology of the heart while also learning about the common heart conditions and medication and treatments for these conditions. That same week they may be caring for a patient with heart disease in a healthcare setting to help transfer the knowledge learned from theory into practice.

Our conversations around transferring knowledge in authentic assessment tasks highlighted the challenge of articulating our experiences. We struggled to capture the complexity of both the learning and the assessment tasks. In fact, Lisa noted that even for instructors in the international pre-service teaching program, the levels of complexity inherent in the transfer of knowledge required were not apparent until the instructors reflected on how well the students had demonstrated their learning.

Perhaps one of the biggest challenges in assessing the transfer of knowledge to real-world settings is moving beyond traditional assessment methods such as multiple-choice examinations and essays (Yates et al., 2015). While it may take some extra time and creativity, it is important to match the learning aims with the proper assessment tasks. This may require the incorporation of a wide variety of methods of assessment - case studies, oral presentations, video representations, 
collaborative tasks, model prototypes, etc.- to generate a more robust understanding of students' ability to apply learning. Even when examinations are deemed necessary, Villaroel et al. (2020) challenged instructors to include elements of realism, cognitive challenge, and transfer of knowledge through authentic evaluative judgement in the design and grading of examinations.

\section{Element \#4: Metacognition as a Component of Authentic Assessment}

John Dewey (1933) reasoned we learn more from reflecting on our experiences than from the actual experiences themselves. Ashford-Rowe et al. (2014) encouraged integrating opportunities to reflect on learning processes within authentic assessment tasks to foster critical reflection, self-evaluation, and personal development. Critical reflection can enable students to extend learning experiences beyond the classroom, make important links between different content areas, and enhance understanding of the processes required to obtain satisfactory outcomes or performances (Ashford-Rowe et al., 2014). Regardless of the field, research supports the value of reflection to deepen learning. As Kolb and Kolb (2009) stated, "when a concrete experience is enriched by reflection, given meaning by thinking, and transformed by action, the new experience created becomes richer, broader, and deeper" (p. 309).

LORELLI: Reflection is purposefully baked into nursing practice through a five-step circular nursing process that guides patient-centered care: assessment, diagnosis, planning, implementation, and evaluation. During the evaluation step, nursing students and practicing nurses reflect on what happened during the first four steps to inform future care. For students, this learning process is often demonstrated through verbalizing care plans and documentation in patient charts.

KIM: In teacher education, we encourage our students to engage in critical reflection to connect and ground their learning experiences. However, students sometimes struggle with what it means to reflect in an academic sense. Students may respond to reflective activities by writing surface-level descriptions of their activities or by venting personal feelings rather than critically exploring assumptions and meanings of experiences and developing alternative ways of seeing and acting. While reflection is a universally valued skill within the field of education, I know I have not always found the best way to explain to my students what exactly reflection is and what it isn't.

When discussing how metacognition is integrated into assessments in our classrooms, we identified an opportunity to be more purposeful and strategic. We talked about the importance of providing students with more structure and guidance to help them derive meaningful learning through reflection. Perhaps this will involve modelling our own reflective practice, encouraging students to visually 
represent their learning through images, or exploring other modalities. Because metacognition has been positively correlated with transfer of learning as well, it is worth our time and energy to prioritize such reflective activities (Scharff et al., 2017). As with other aspects of authentic assessment, instructors will need to be creative with contextually relevant strategies to purposefully integrate metacognitive processes that may increase students' ability to reflect on and reapply the knowledge they have gained (Zizka, 2020).

\section{Element \#5: The Value of Collaboration}

Opportunities to co-produce knowledge, work together to build products, and collaboratively complete challenging tasks are essential components in authentic assessment activities. Working together allows students to navigate diverse perspectives and encourages communication beyond a single component of the curriculum. Collaborations may involve student-student partnerships, teacherstudent collaboration, and participation in a community of learners (Healey et al., 2016). These partnerships present opportunities to develop support systems, build understanding of different points of view, model and practice cooperation, develop critical thinking skills, engage in problem solving, and actively participate in the learning process (Laal \& Ghodsi, 2012). Involving students as partners in developing tasks and assessments results in a sense of individual and shared ownership that empowers and promotes accountability and cooperation, which are necessary in real-world contexts (Meer \& Chapman, 2015).

LISA: I often ask my graduate students to reflect on their work and grade themselves. Then I invite them to share their grades with one or two partners and talk about why they provided that evaluation for themselves. Their conversations start to shift: different perspectives are offered, examples are provided, and support systems begin to develop. I see barriers start to come down and trust and compassion begin to form among the learners. This allows them to go a step further and begin to develop criteria based on their experience with self-and peerassessment.

LORELLI: I purposely include student peer review in many of my assessments as a way for nursing students to collaboratively build on each other's strengths and to create a stronger final product. However, this requires taking time to focus on the value of reciprocity in giving and receiving feedback as a gift rather than as a critique.

KIM: I agree. It is time consuming. I have collaboratively designed rubrics with undergraduate students who then use the criteria to reflect and self-assess prior to submitting their work. I could create a rubric much more quickly on my own, but then the students would not have the opportunity to think through and discuss together what good work looks 
like.

While collaboration requires time and tactful negotiation, this challenging work often leads to rich learning. Collaboration between students can support them in taking greater responsibility for their learning, help them develop better assessment literacy, and foster a greater ability to think scientifically (Rivers et al., 2017). We can help students better understand the value of working together while providing them with opportunities to collaborate in meaningful ways with autonomy, independence, and choice (Healey et al., 2016).

\section{Element \#6: The Importance of Accuracy in Assessment}

Accuracy in authentic assessment requires that the criteria by which learners' performances or products are assessed relate to measures used in a real-world situation. As such, the performance or product has a means of "determining the degree of authenticity inherent within the activity" (Ashford-Rowe et al., 2014. p. 209). An authentic assessment task should include criteria based on insights from the field rather than solely matched to classroom curriculum content and settings (Herrington, 2006). When the learning criteria do not align with disciplinary norms and practices, students may feel disconnected from or disengaged with tasks that seem to be artificial. Of equal importance is providing learners with the assessment criteria ahead of time so they can gradually develop the performance or product with an understanding of and ability to judge their own performance through selfand/or peer-assessment. Educators can also support students' learning by providing them with concrete examples that exemplify the expectations required to satisfy standards set out by the field they are preparing to enter (Villarroel et al., 2018).

LISA: The way I make meaning of this element is through the use of rubrics. When I develop a rubric, I include examples of different levels of criteria to support students' ability to see the progression of their performance and how it relates to real-world settings. Rubrics provide both structure and flexibility to assess the wide range of possibilities that emerge from open-ended authentic tasks in diverse contexts and fields.

LORELLI: In nursing, accuracy is often essential, especially when it comes to tracking patients' vital signs and administering medication, for example. We often say "death by decimal" to drive home the importance of accurate math calculations. For some nursing assessments, such as math exams, 100\% accuracy is expected. In these cases, as in the field, accuracy is not a spectrum: it simply is or isn't.

We continue to reflect on how we can be more intentional in supporting students in developing and using authentic criteria for assessment. Since we know students' engagement in the assessment process contributes to enhanced student learning 
outcomes (Boud, 2000), we need to help them understand and internalize the criteria for accuracy and quality in our fields.

\section{Element \#7: The Role of the Assessment Environment and the Tools Used to Deliver the Assessment Task}

Ashford-Rowe et al. (2014) argued the tools and environment used to create authentic products or performances should closely resemble those used in the discipline or field. However, recreating a real-world environment can be challenging. While science labs offer a direct correlation to the field, tools used to create authentic environments may include broader cultural elements such as language, graphics, and topics to make the assessment tasks feel more relevant for students (Kendle \& Northcote, 2000). The concept of simulation is not new, but enhanced technologies offer new possibilities within higher education. Simulation experiences can promote the development of higher-level problem solving, decision-making, and creative thinking skills (Bradley \& Postlethwaite, 2003; Rauen, 2001). When real-world practical settings are not possible or not safe, simulation is "a method whereby an artificial or hypothetical experience is created that engages the learner in an activity that reflects real-life conditions but without the risk-taking consequences of an actual situation" (Bastable, 1997, p. 270).

LORELLI: My Faculty of Nursing invested in a state-of-the-art simulation centre to support nursing students to develop clinical skills in a safe and standardized environment. The simulation centre offers a range of learning spaces that closely resemble healthcare settings including hospital rooms, clinics, and homecare settings. In this space, we have mannequins that speak and have palpable pulses and blood pressures, as well as mannequins that give birth, allowing students to engage in real-world nursing tasks in a replicated healthcare environment.

KIM: When pre-service teachers are in K-12 classrooms with students, the learning curve is steep, and assessment remains challenging. There are so many factors at play simultaneously when you are in a real teaching environment, using real tools, that we can only assess a subset of competencies at any given time. So while the complexity of the field experience is essential to the learning process, it becomes even more important to provide clear, meaningful feedback that promotes growth rather than overwhelming people.

In the same way that our curiosity was piqued regarding performances and products in other fields, we wondered how other disciplines might address this issue of including authentic environments for assessment and found this to be a gap in the SoTL literature. We imagine that others might consider including appropriate technical language, tools, and visuals to approximate real-world practices. These 
may be incorporated in assessment strategies as well as in teaching strategies. We look forward to seeing how others take up these questions in future research.

\section{Element \#8: The Importance of Formally Designing an Opportunity to Discuss and Provide Feedback.}

There is a plethora of research on the importance of feedback for learning (Boud \& Molloy, 2013; Wanner \& Palmer, 2018; Zhang \& Zheng, 2018). The element of authentic assessment goes beyond the traditional idea of grading to include "feedback as both guidance and a means of determining areas for improvement" (Ashford-Rowe et al., 2014, p. 210). While grading is usually limited to educational contexts, giving and receiving feedback is a professional practice in every field. When designing for authentic feedback, it is important to keep in mind how feedback is given in that particular field. For example, in architecture or design, a studio critique process is more authentic than comments on a paper. In the fine arts, verbal comments from an adjudication panel may best align with how those in the field normally provide evaluation and feedback. Learning how to provide feedback to peers also helps learners internalize and articulate aspects of good practice and become more effective in self-assessing (Boud \& Molloy, 2013; Nicol, 2010).

LORELLI: In nursing education practice, there are often critical learning junctures that require timely feedback, such as when trying a new skill for the first time. When a critical learning juncture occurs and is identified by the learners or the instructors, there is a pause in student action, and knowledge sharing and feedback is provided in real time.

LISA: Timely, authentic feedback is important when working with preservice teachers as well. It is common for feedback to be provided directly after "practice-teaching" exercises, usually focused on how effectively the learning objective of that lesson has been achieved. Often feedback is provided by the instructor and the student's peers in a safe environment. This helps redirect the student to areas they need to focus on most, such as tying the lesson activities to the learning objective, time management, or voice intonation skills.

While providing feedback is considered central to teaching practice, we can be more intentional about providing opportunities for students to give each other feedback as well. We want to normalize these practices and provide effective strategies to give and receive peer feedback. Interestingly, students may perceive giving peer feedback to be more useful than receiving peer feedback and also believe it enhances their learning and understanding of assignments (Gaynor, 2019). Fostering a sense of collaboration and creating a positive learning environment can encourage positive peer-review experiences. Gaynor (2019) argued that it should be made explicit to students that substantial effort in the reviewing role leads to better understanding and higher quality feedback for all. 


\section{CONCLUSION/IMPLICATIONS}

We believe that this conversational model is at the heart of informal SoTL collaborations - connecting theory with practice, finding new ways to articulate what we are doing, diving into the literature to see what the research shows, sharing strategies with colleagues, and reflecting together on ways to strengthen teaching and learning practices. Our conversations highlighted that, although the theoretical framework and terminology of authentic assessment was new to us, the idea that assessments can and should connect to real-world activities in our fields resonated with our lived experiences of what is and what works in our teaching practices. These conversations, propelled by the interplay of questions in Hutchings' (2000) taxonomy of SoTL inquiry, provided opportunities to reflect individually and collaboratively about what is possible. We have been able to articulate aspects of our teaching and assessment practice in new ways and to glean insights from other fields that enhance our ability to be more intentional moving forward.

\section{AUTHOR BIOGRAPHY}

Dr. Kimberley Grant, grantka@ucalgary.ca, is an Educational Development Consultant at the Taylor Institute for Teaching and Learning and Adjunct Assistant Professor at the Werklund School of Education. She currently leads a teaching development program for academic staff and consults on program-level curriculum development and review.

Dr. Lisa Fedoruk is an Educational Development Consultant at the University of Calgary. She collaborates with faculty, postdoctoral scholars and students to facilitate, guide and support workshops, programming, and resources related to the Taylor Institute's Certificates in University Learning and Teaching and Teaching Assistant Orientation.

Dr. Lorelli Nowell is an Assistant Professor, and she currently holds a Teaching and Learning Research Professorship. Her emerging program of research focuses on studying innovations in teaching and learning, the professional learning and development of educators, and mentorship to support teaching and learning practices. 


\section{REFERENCES}

Ashford-Rowe, K., Herrington, J., \& Brown, C. (2014). Establishing the critical elements that determine authentic assessment. Assessment \& Evaluation in Higher Education, 39(2), 205-222. https://doi.org/10.1080/02602938.2013.819566

Archbald, D. A., \& Newmann, F. M. (1988). Beyond standardized tests: Assessing authentic achievement in the secondary school. National Association of Secondary Principals.

Bass, R. (1999). The scholarship of teaching: What's the problem? Inventio: Creative Thinking about Teaching and Learning, 1(1), 1-9. https://ctl.uga.edu/_resources/imported/mainBass 1999 Inventio.pdf

Bastable, S. B. (1997). Nurse as educator: Principles of teaching and learning. Jones and Bartlett.

Bessa, B. R., Santos, S., \& Duarte, B. J. (2019). Toward effectiveness and authenticity in PBL: A proposal based on a virtual learning environment in computing education. Computer Applications in Engineering Education, 27(2), 452-471. https://doi.org/10.1002/ cae.22088

Boud, D. (2000). Sustainable assessment: Rethinking assessment for the learning society. Studies in Continuing Education, 22(2): 151-167. https://doi.org/10.1080/713695728

Boud, D., \& Molloy, E. (Eds.). (2013). Feedback in higher and professional education: Understanding it and doing it well. Routledge.

Bradley, P., \& Postlethwaite, K. (2003). Simulation in clinical learning. Medical Education, 37(s1), 1-5.

Burrack, F. (2018). Authentic assessment. In The SAGE encyclopedia of educational research, measurement, and evaluation. https://doi.org/10.4135/9781506326139

Dewey, J. (1933). How we think: A restatement of the relation of reflective thinking to the educative process. Heath.

Fook, C. Y., \& Sidhu, G. K. (2010). Authentic assessment and pedagogical strategies in higher education. Journal of Social Sciences, 6(2), 153-161.

Gaynor, J. W. (2019). Peer review in the classroom: Student perceptions, peer feedback quality and the role of assessment. Assessment \& Evaluation in Higher Education, 45(5), 1-18. https://doi.org/10.1080/02602938.2019.1697424

Gulikers, J. T. M., Bastiaens, T. J., \& Kirschner, P. A. (2004). A five-dimensional framework for authentic assessment. Educational Technology Research and Development, 52(3), 67-86. https://doi.org/10.1007/BF02504676

Hager, P., \& Hodkinson, P. (2009). Moving beyond the metaphor of transfer of learning. British Educational Research Journal, 35(4), 619-638. https://doi.org/10.1080/01411920802642371

Haynes, K. (2010). Critical reflections on authentic teaching: A personal account. Reflective Practice, 11(3), 299-306. 
https://doi.org/10.1080/14623943.2010.487369

Healey, M., Flint, A., \& Harrington, K. (2016). Students as partners: Reflections on a conceptual model. Teaching \& Learning Inquiry, 4(2), 1-13. https://doi.org/10.20343/teachlearninqu.4.2.3

Herodotou, C., Muirhead, D. K., Aristeidou, M., Hole, M. J., Kelley, S., Scanlon, E., \& Duffy, M. (2018). Blended and online learning: A comparative study of virtual microscopy in higher education. Interactive Learning Environments 1-16. https://doi.org/10.1080/10494820.2018.1552874

Herrington, J. (2006, October 13-17). Authentic e-learning in higher education: Design principles for authentic learning environments and tasks [Paper presentation]. World Conference on E-Learning in Corporate, Government, Healthcare, and Higher Education (ELEARN), Honolulu, HI, United Stated. http://researchrepository.murdoch.edu.au/5247

Hutchings, P. (2000). Approaching the scholarship of teaching and learning. In P. Hutchings (Ed.), Opening lines: Approaches to the scholarship of teaching and learning (pp. 1-10). The Carnegie Foundation for the Advancement of Teaching.

Kendle, A., \& Northcote, M. (2000). The struggle for balance in the use of quantitative and qualitative online assessment tasks. Proceedings of the 17th Annual Conference of the Australasian Society for Computers in Learning in Tertiary Education. Southern Cross University Press.

Koh, K. H., Tan, C., \& Ng, P. T. (2012). Creating thinking schools through authentic assessment: The case in Singapore. Educational Assessment, Evaluation and Accountability, 24(2), 135-149. https://doi.org/10.1007/s11092-011-9138-y

Kolb, A., \& Kolb, A. (2009). The learning way: Meta-cognitive aspects of experiential learning. Simulation and Gaming, 40(3), 297-327. https://doi.org/10.1177/1046878108325713

Laal, M., \& Ghodsi, S. M. (2012). Benefits of collaborative learning. Procedia Social and Behavioral Sciences, 31, 486-490. https://doi.org/10.1016/j.sbspro.2011.12.091

Maxwell, T. W. (2012). Assessment in higher education in the professions: Action research as an authentic assessment task. Teaching in Higher Education, 17(6), 686-696. https://doi.org/10.1080/13562517.2012.725220

Meer, N., \& Chapman, A. (2014). Co-creation of marking criteria: Students as partners in the assessment process. Business and Management Education in $H E, 1-15$. https://www.tandfonline.com/doi/full/10.11120/bmhe.2014.00008

Nelles, L. J., Smith, C. M., Lax, L. R., \& Russell, L. (2011). Translating face-toface experiential learning to video for a web-based communication program. The Canadian Journal for the Scholarship of Teaching and Learning, 2(1). https://doi.org/10.5206/cjsotl-rcacea.2011.1.8

Newmann, F. M., Marks, H. M., \& Gamoran, A. (1996). Authentic pedagogy and student performance. American Journal of Education, 104(4), 280-312. 
Nicol, D. (2010). The foundation for graduate attributes: Developing selfregulation through self and peer-assessment. QAA Scotland. https://www.reap.ac.uk/Portals/101/Documents/PEER/Graduate\%20attrib utes\%20and\%20peer\%20review.pdf

Oblinger, D. G. (2004). The next generation of educational engagement. Journal of Interactive Media in Education, 2004(1), 10. https://doi.org/10.5334/2004-8-oblinger

Rauen, C. A. (2001). Using simulation to teach critical thinking skills: You can't just throw the book at them. Critical Care Nursing Clinics of North America, 13(1), 93-103. https://doi.org/10.1016/S0899-5885(18)30070-4

Rivers, J., Smith, A. B., Higgins, D., Mills, R., Maier, A. B., \& Howitt, S. M. (2017). Asking and answering questions: Partners, peer learning, and participation. International Journal for Students as Partners, 1(1). https://doi.org/10.15173/ijsap.v1i1.3072

Roxå, T., \& Mårtensson, K. (2009). Significant conversations and significant networks - Exploring the backstage of the teaching arena. Studies in Higher Education, 34(5), 547-559. https://doi.org/10.1080/03075070802597200

Scharff, L., Draeger, J., Verpoorten, D., Devlin, M., Dvorakova, L. S., Lodge, J. M., \& Smith, S. (2017). Exploring metacognition as support for learning transfer. Teaching \& Learning Inquiry, 5(1), 1-14. https://doi.org/10.20343/5.1.6

Villarroel, V., Bloxham, S., Bruna, D., Bruna, C., \& Herrera-Seda, C. (2018). Authentic assessment: Creating a blueprint for course design. Assessment \& Evaluation in Higher Education, 43(5), 840-854. https://doi.org/10.1080/02602938.2017.1412396

Villarroel, V., Boud, D., Bloxham, S., Bruna, D., \& Bruna, C. (2020). Using principles of authentic assessment to redesign written examinations and tests. Innovations in Education and Teaching International, 57(1), 38-49. https://doi.org/10.1080/14703297.2018.1564882

Wanner, T., \& Palmer, E. (2018). Formative self- and peer-assessment for improved student learning: The crucial factors of design, teacher participation and feedback. Assessment \& Evaluation in Higher Education, 43(7), 1032-1047. https://doi.org/10.1080/02602938.2018.1427698

Weaver, K., Brown, D., Bostock, J., \& Kirby, J. (2020). How far does VLE selfdirected study facilitate improvements in written, practical and overall assessment results? Sports therapy case study. Innovations in Education and Teaching International. https://doi.org/10.1080/14703297.2020.1722201

Wiggins, G. P. (1990). The case for authentic assessment. Practical Assessment, Research \& Evaluation, 2(2), 1-3.

Wiggins, G. P. (1993). Assessing student performance: Exploring the purpose and limits of testing. Jossey-Bass.

Yates, T., Wilson, J., \& Purton, K. (2015). Surveying assessment in experiential 
learning: A single campus study. The Canadian Journal for the Scholarship of Teaching and Learning, 6(3), 1-27. https://doi.org/10.5206/cjsotl-rcacea.2015.3.4

Zhang, L., \& Zheng, Y. (2018). Feedback as an assessment for learning tool: How useful can it be? Assessment and Evaluation in Higher Education, 43(7), 1120-1132. https://doi.org/10.1080/02602938.2018.1434481

Zizka, L. (2020). Reflection and SoTL: Putting reflection (back) on faculty radar. In R. C. Plews \& M. L. Amos (Eds.), Evidence-based faculty development through the Scholarship of Teaching and Learning (SoTL) (pp. 96-120). IGI Global. 